\title{
Small island, big threats
}

Written by: Balázs Gyimesi, OECD Observer

Last update: 28 January 2020



Small islands, big threats 1 I A street destroyed by the earthquake in downtown Port-au-Prince, Haiti, on 3 February 2010.

Last year, actor Sean Penn called on world leaders to help Haiti deal with the "looming existential threat" of climate change.

Mr Penn was speaking at the One Planet Summit in Paris in December, where small islands commanded everyone's attention in the wake of a series of destructive hurricanes that showed how Haiti and similar small island developing states-sometimes referred to as SIDS-are particularly affected by extreme weather events and natural disasters. More than 335 major natural catastrophes have hit them since 2000, resulting in damage estimated at US\$22.7 billion. 
Small islands, big threats 2

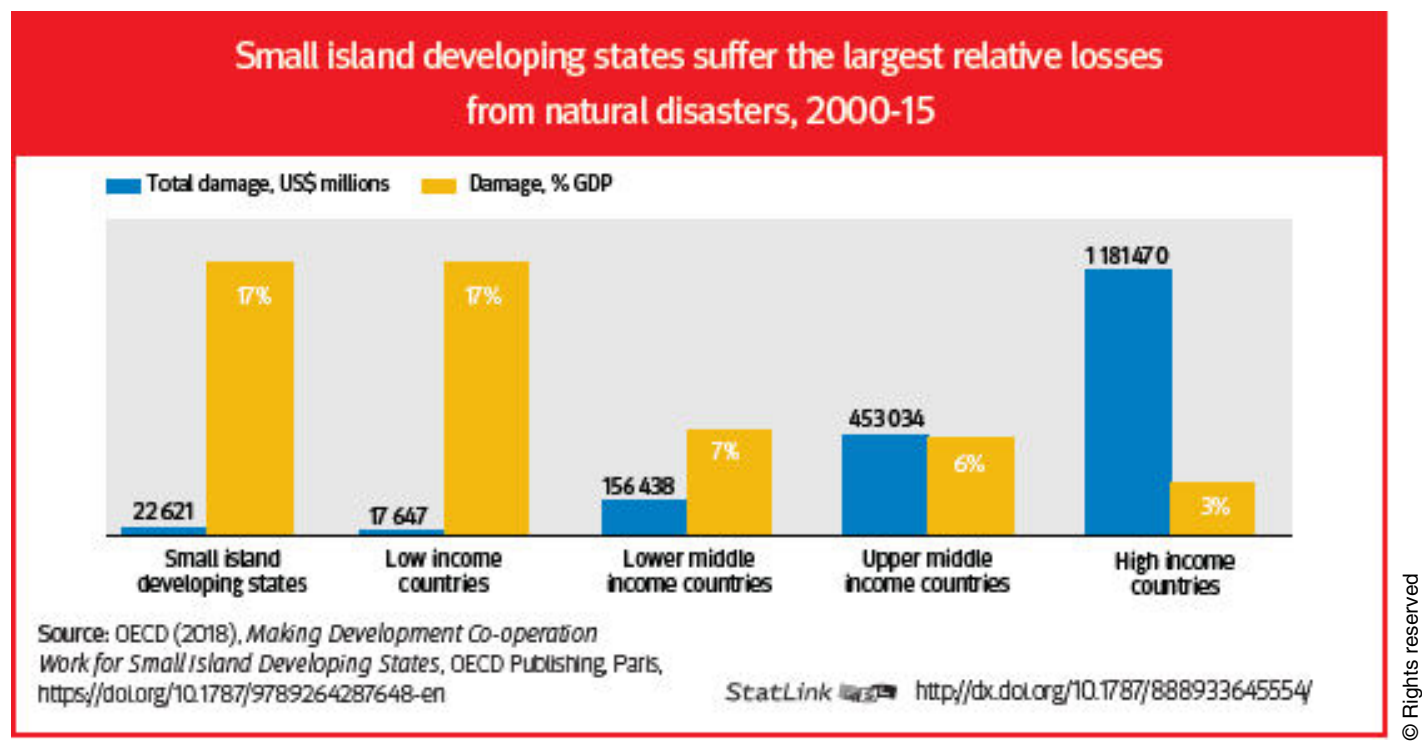

Small islands, big threats chart - Small island developing states suffer the largest relative losses from natural disasters, 2000-2015

OECD (2018), Making Development Co-operation Work for Small Island Developing States, OECD Publishing, Paris, https://doi.org/10.1787/9789264287648-en

In fact, such disasters destroyed $17 \%$ of small island developing states' GDP between 2000 and 2015, whereas high income countries lost just 3\% of their GDP to natural catastrophes in the same period. According to Making Development Cooperation Work for Small Island Developing States, the relatively poor island states are not equipped to respond to extreme events, while climate change has increased the severity and frequency of extreme weather events by an estimated $40-80 \%$, posing additional challenges.

Development co-operation can help mitigate the effects of disasters, the report argues, and help make small island states more resilient. Short-term disaster response from humanitarian donors must be linked with long-term financial support and be mainstreamed into development planning and financing.

COECD Observer September 2018

\section{References}

OECD (2018), Making Development Co-operation Work for Small Island Developing States, OECD Publishing, Paris, http://dx.doi.org/ https://doi.org/ 10.1787/9789264287648-en 